\title{
Evolutionary and Prognostic Aspects of Thrombolysed Patients for Acute Coronary Syndrome ST+ at CHU Ernesto Guevara De La Serna. Las Tunas (Cuba)
}

\author{
Boubacar Sonfo ${ }^{*}$, Hamidou Oumar Bâ ${ }^{2}$, Youssouf Camara ${ }^{1}$, Coumba Thiam ${ }^{1}$, \\ Ibrahima Sangaré ${ }^{2}$, Massama Konaté ${ }^{3}$, Sidibé Samba4, Sako Mariam4, Asmaou Keita5, \\ Coulibaly Souleymane ${ }^{4}$, Ilo Bella Diall4, Menta Ichaka², Amadou Khalil Traoré1, \\ Yudelquis Ojeda Riquenes ${ }^{6}$, Maikel Santos Medina ${ }^{6}$ \\ ${ }^{1}$ Cardiology Department of CHU Kati, Bamako, Mali \\ ${ }^{2}$ Cardiology Department CHU Gabriel Touré, Bamako, Mali \\ ${ }^{3}$ Internal Medicine Service, Mali Hospital, Bamako, Mali \\ ${ }^{4}$ Cardiology Department CHU Point G, Bamako, Mali \\ ${ }^{5}$ Cardiology Department CHU Mère-Enfant, Bamako, Mali \\ ${ }^{6}$ Cardiology Department CHU Ernesto Guevara, Las Tunas, Cuba \\ Email: *sonfo20032001@yahoo.fr
}

How to cite this paper: Sonfo, B., Bâ, H.O., Camara, Y., Thiam, C., Sangaré, I., Konaté, M., Samba, S., Mariam, S., Keita, A., Souleymane, C., Diall, I.B., Ichaka, M., Traoré, A.K., Riquenes, Y.O. and Medina, M.S. (2020) Evolutionary and Prognostic Aspects of Thrombolysed Patients for Acute Coronary Syndrome ST+ at CHU Ernesto Guevara De La Serna. Las Tunas (Cuba). World Journal of Cardiovascular Diseases, 10, 437-445. https://doi.org/10.4236/wjcd.2020.107043

Received: May 21, 2020

Accepted: July 12, 2020

Published: July 15, 2020

Copyright ( 2020 by author(s) and Scientific Research Publishing Inc. This work is licensed under the Creative Commons Attribution International License (CC BY 4.0).

http://creativecommons.org/licenses/by/4.0/

\begin{abstract}
Introduction: Acute myocardial infarction (IDM) occupies the first place in terms of mortality, among ischemic pathologies. Thrombolysis in the case of medical treatment for acute myocardial infarction (AMI) is undoubtedly the most revolutionary performed to date in this context, with a significant reduction in the mortality rate. The aim of our study was to describe the epidemiological aspects, the criteria for myocardial reperfusion post thrombolysis, the complications during thrombolysis and the complications of acute myocardial infarction in the cardiology department of the CHU Ernesto Guevara De La Serna of Las Tunas (Cuba). Methods: A retrospective cross-sectional descriptive study was carried out from June 2009 to December 2011. The patients hospitalized during this period in the USIC (coronary intensive care unit) for SCA ST(+) were included in the study. The variables studied were: Age, sex, myocardial reperfusion criteria, complications during thrombolysis and complications of myocardial infarction. Results: A total of 207 patients were included. The male sex represented $72.5 \%$ of the cases, giving a sex ratio of 2.63 . The age group $>60$ years was predominant with $54.2 \%$ of the cases. Thrombolysed patients represented $65.2 \%$ of the cases. Myocardial reperfusion criteria were observed in the majority of thrombolysed pa-
\end{abstract}


tients: relief of precordial pain (77\%), regression of the ST segment to $50 \%$ of its previous level (81.5\% of patients). Bleeding was observed in $1.5 \%$ of thrombolysed cases. Complications were encountered in $57 \%$ of non thrombolysed patients with a lethality of $5.6 \%$. Conclusion: The male sex was the most affected. Thrombolysis was effective in the majority of patients. The post thrombolysis bleeding rate was low. More than half of the cases of SCA $\mathrm{ST}(+)$ not thrombolysed presented complications.

\section{Keywords}

Acute Coronary Syndrome, Thrombolysis, CHU, Las Tunas, Cuba

\section{Introduction}

One of the leading causes of cardiovascular death and disability is ischemic heart diseases [1] [2] [3]. Among ischemic pathologies, acute myocardial infarction ranks first in terms of mortality. Fibrinolytic therapy for medical treatment of acute myocardial infarction (AMI) is probably the most revolutionary to date in this context [4] [5], with a significant reduction in the mortality rate. According to international reports, this treatment has been used since the $1950 \mathrm{~s}$, but with reservations, in 1970 there was an increase in the number of thrombolysed patients. With the belief that the thrombus was a consequence and not the cause of death, thrombolysis was abandoned to be resumed in the years 1982, with the realization of the angiography which demonstrated that the thrombus was the main cause of the infarction acute myocardium in more than $80 \%$ of cases, hence thrombolysis has again taken an important place in the treatment of acute myocardial infarction [6]. Large scale multicenter studies have demonstrated: the effectiveness of different fibrinolytic agents in reducing the infarction area, a decrease in mortality, that there were no significant differences between fibrinolytics in terms of efficacy and that intracoronary thrombolysis was not superior to intravenous thrombolysis. Treatment is beneficial only for cases of myocardial infarction with precordialgia [7] [8]. Clarifications were made on the time limit for initiating thrombolysis taking into account the onset of angina pain. A thrombolysis performed in the first 6 hours of the onset of symptoms reduces the infarct area, after 6 hours until 12 hours, we have a reduction in the negative effect of ventricular remodeling, with a significantly lower benefit compared the first 6 hours. The best results are obtained, when thrombolysis is carried out in the first hours of the onset of symptoms [9]. Despite all these clarifications on the benefits of fibrinolytic therapy, we have not achieved a good indicator of the use of this drug in the world. Studies carried out at national level have found a low rate of thrombolysed cases with the main cause of slowness in reaching emergency services [10] [11] [12]. Acute coronary syndrome is the leading cause of death (53.7\%) among cardiovascular pathologies according to the annual report of the regional health department of Las Tunas [13] [14]. Previous studies 
in the region have indicated that the majority of patients with acute coronary syndrome have not had thrombolysis [15]. An increase in the number of thrombolysed patients in our region makes it possible to reduce mortality and improve the prognosis of cases of acute myocardial infarction. Given the importance of fibrinolytic therapy in the management of acute myocardial infarction. We decided to carry out this work with the aim of describing the epidemiological, evolutionary and prognostic aspects of thrombolysed patients hospitalized at CHU Ernesto Guevara De La Serna de Las Tunas.

\section{Materials and Methods}

A retrospective and descriptive study was carried out from June 2009 to December 2011 in the cardiology department of the CHU Ernesto Guevara De la Serna of Las Tunas (Cuba). Inclusion criteria: patients hospitalized during this period in the Coronary intensive care unit with the diagnosis of acute coronary syndrome with ST shift (SCA ST+) over clinical and electrocardiographic criteria. The data were collected from medical record. The variables studied were: Socio-demographic characteristics (Age, sex), myocardial reperfusion criteria (clinical and electrocardiographic), complications during thrombolysis, complications of myocardial infarction.

Definition of terms:

Thrombolysis: intravenous thrombolysis consists in injecting a substance capable of dissolving the clot that clogs the coronary artery.

The product used was streptokinase, which is a non enzymatic protein produced by the beta hemolytic streptococcus.

Presentation: 750,000 and 1500,000 IU.

Dosage: $1500,000 \mathrm{IU}$ in $200 \mathrm{ml}$ of $0.9 \%$ saline solution or in a $5 \%$ glucose serum by intravenous infusion for 1 hour.

Thrombolysis was performed by the nurse assisted by the cardiologist, who was on duty or on call depending on the time of arrival of patients in the cardiology department.

Reperfusion criteria:

- Clinic: relief or disappearance of precordial pain after completing thrombolysis.

- Electrocardiographic: regression of the ST segment to $50 \%$ of the initial elevation level, during the 90 minutes following thrombolysis, appearance of reperfusion arrhythmias.

Complications:

- Complications of thrombolysis: these are complications that appear during or immediately after completing thrombolysis.

- Complications of acute myocardial infarction: These are complications that occur depending on the extent of the infarction area. There may be: a pump failure with the appearance of different classes of ventricular dysfunction according to the Killip Kimbal (KK) classification, ischemic, electrical complications, cessation of the mechanical activity in the heart. 
Exclusion criteria: patients with infarction without ST segment elevation.

Datacollection and processing.

The EPI Info V6 program for Windows was used for data collection and analysis. The results presented in the form of tables and graphs.

\section{Ethical Considerations:}

All patients give their verbal consent, being informed about the procedures in the study, their harmless character and even anonymous treatment of their data.

\section{Results}

A total of 207 patients were included. The age group $>60$ years was predominant $(54.2 \%)$, the male sex represented $72.5 \%$ of the cases, a sex ratio of 2.63 (Table 1). The predominance of males in our study could be explained by the fact that women in the fertile stage of their lives are protected by estrogens, which increase high density lipoproteins, which are considered to be anti atherogenic, fulfilling protective functions and thereby decreasing the incidence of heart attacks in women especially those under 50 years. Thrombolysed patients represented $65.2 \%$ of the cases (Table 2). The patients had chest pain before thrombolysis, the majority of patients (77\%) had relief of precordial pain after thrombolysis, regression of the ST segment to $50 \%$ of its previous level was observed in $81.5 \%$ of cases, half of the patients presented with reperfusion arrhythmia (Table 3). Uncomplicated patients during thrombolysis accounted for $82.2 \%$ of the cases. Hypotension was the most reported complication $10.4 \%$. Bleeding was observed in $1.5 \%$ of patients (Figure 1). Uncomplicated thrombolysed acute myocardial infarction accounted for $95 \%$. The most common complications were respectively: left ventricular dysfunction (2.5\%) and ischemic complications (1.5\%). In non-thrombolysed patients, complications were observed in $57 \%$ of the cases, left ventricular dysfunction (30.6\%), followed by ischemic complications (11.1\%) were the most represented. Complications were more frequent in cases of non-thrombolysed acute myocardial infarction compared to cases of thrombolysed acute myocardial infarction, hence the importance of thrombolysis in patients with acute myocardial infarction ST+. The thrombolysed patients presented a favorable evolution compared to the non-thrombolysed patients with a lethality of 5.6\% (Table 4).

Table 1. Distribution according to sex and age group of patients hospitalized for acute coronary syndrome ST+.

\begin{tabular}{ccccccc}
\hline \multirow{2}{*}{ Age group (years) } & \multicolumn{2}{c}{ Male } & \multicolumn{2}{c}{ Female } & \multicolumn{2}{c}{ Total } \\
\cline { 2 - 7 } & No & $\%$ & No & $\%$ & No & $\%$ \\
\hline Under 40 & 10 & 66.6 & 5 & 33.4 & 15 & 7.2 \\
$40-60$ & 60 & 75 & 20 & 25 & 80 & 38.6 \\
Over 60 & 80 & 71.4 & 32 & 28.6 & 112 & $\mathbf{5 4 . 2}$ \\
Total & 150 & $\mathbf{7 2 . 5}$ & 57 & 27.5 & 207 & 100 \\
\hline
\end{tabular}

Source: medical record. 
Table 2. Distribution according to thrombolysed and non thrombolysed patients.

\begin{tabular}{ccc}
\hline Distribution of patients & Number & Percentage \\
\hline Thrombolysed patients & 135 & 65.2 \\
Non thrombolysed patients & 72 & 34.8 \\
\hline
\end{tabular}

Source: Dossier medical record.

Table 3. Effectiveness of thrombolytic treatment according to clinical and electrocardiographic criteria.

\begin{tabular}{ccccccc}
\hline \multirow{2}{*}{ Reperfusion criteria } & \multicolumn{2}{c}{ Yes } & \multicolumn{2}{c}{ No } & \multicolumn{2}{c}{ Total } \\
\cline { 2 - 7 } & Number & $\%$ & Number & $\%$ & Number & $\%$ \\
\hline Clinical & 104 & $\mathbf{7 7}$ & 31 & 23 & 135 & 100 \\
ST segment regression to 50\% & 110 & $\mathbf{8 1 . 5}$ & 25 & 18.5 & 135 & 100 \\
Reperfusion arrhythmia & 70 & $\mathbf{5 1 . 9}$ & 65 & 48.1 & 135 & 100 \\
\hline
\end{tabular}

Source: medical record.

Table 4. The evolution of the infarction according to the Thrombolysed cases and the non Thrombolysed.

\begin{tabular}{|c|c|c|c|c|c|}
\hline \multicolumn{2}{|c|}{ Evolution of acute myocardial infarction } & \multicolumn{2}{|c|}{ Thrombolysed cases } & \multicolumn{2}{|c|}{ Non Thrombolysed cases } \\
\hline Complications & & Number & $\%$ & Number & $\%$ \\
\hline \multirow{3}{*}{ Left Ventricular dysfunction } & KK-II & 2 & 1.5 & 10 & 13.9 \\
\hline & KK-III & - & - & 7 & 9.7 \\
\hline & KK-IV & 1 & 1 & 5 & 7 \\
\hline \multicolumn{2}{|c|}{ Electrical complications } & 2 & 1 & 5 & 7 \\
\hline \multicolumn{2}{|c|}{ Ischemic Complications } & 2 & 1.5 & 8 & 11.1 \\
\hline \multicolumn{2}{|l|}{ Death } & - & - & 4 & 5.6 \\
\hline \multicolumn{2}{|l|}{ Other complications } & - & - & 2 & 2.8 \\
\hline \multicolumn{2}{|c|}{ Without complications } & 128 & 95 & 31 & 43.1 \\
\hline
\end{tabular}

Other complications: pericarditis post infarction, mitral insufficiency post infarction. Source: Medical record.

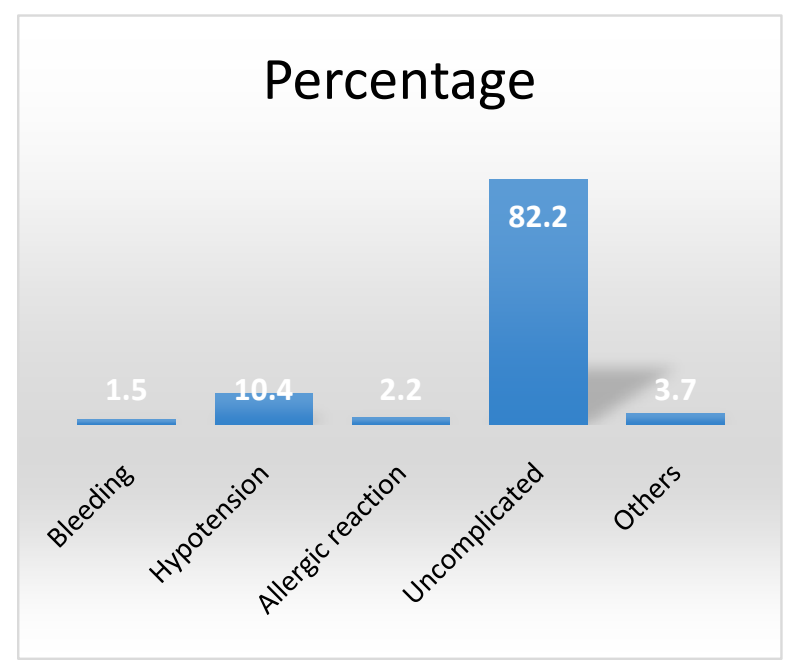

Figure 1. Complications during thrombolysis. Others: Nausea, vomiting. Source: medical record. 


\section{Discussion}

A total of 207 patients were included. The age group $>60$ years was predominant (54.2\%). The male sex was the most represented (72.5\%) of cases or a sex ratio of 2.63. A similar result was found in a study by Albis and Guerrero in Columbia [16]. On the other hand, our result is slightly lower than a study carried out in Spain where the male sex represented $88 \%$ of the cases [17]. This predominance of male in our study can be explained by the fact that women in the fertile stage of their lives are protected by estrogens, which increases high density lipoproteins, which are considered to be anti atherogenic, fulfilling protective functions, which decreases the incidence of heart attacks in women, especially those under the age of 50 [2] [18]. In our study $65.2 \%$ of the patients were thrombolysed, lower proportion was found by Izaguirre in Havana [11] and Kannel [19], considerably lower (37\%) in the study carried out by Lopez et al. [20] at the Simon Bolivar People's Clinic. In the absence of the catheterization room for performing coronary angioplasty in our region, thrombolysis remains the essential treatment for cases of acute coronary syndrome with ST shift. A regression of the ST over shift to $50 \%$ after the 90 minutes of thrombolysis was observed in $81.5 \%$ of the cases. This confirms the benefits of thrombolysis when it is performed during the first hours of acute myocardial infarction. Many studies [21] [22] have demonstrated the efficacy of thrombolysis when carried out during the first hours of a heart attack. Efficacy is evaluated through the following reperfusion criteria: an improvement in symptomatology (pain), a regression of the ST segment elevation to $50 \%$ of its previous level and the appearance of reperfusion arrhythmia (this latter is not always present). These results are superior to those encountered in a study carried out in the United States of America [23], in which $50 \%$ of thrombolysis patients presented the reperfusion criteria. Our result is similar to the SAVE study carried out in the United States of America and Canada [19] [24]. These results can be improved by applying fibrinolysis during the first 3 hours of the infarction. Bleeding was observed in $1.5 \%$ of thrombolysed cases. Post thrombolysis bleeding is the most dangerous complication. The bleeding can be light, moderate or severe depending on the type of fibrinolytic used. There are fibrinolytic selective fibrin products that allow lysis of fibrin from the thrombus and non fibrin selective products, which react on the thrombus and on the blood clotting process, which increases the risk of bleeding. The Thrombolytic used in our study was non selective fibrin. A higher result than ours was observed in a study carried out at the Mario Nuñez Military University hospital in Matanzas [25]. Our result is similar to that of the SAVE study carried out in Canada [24] [26]. This result can be explained by the good selection of the candidates according to the criteria of thrombolysis and the establishment of the conditions required for the realization of thrombolysis. The majority of thrombolysis patients (95\%) did not experience any complications. Left ventricular dysfunction and ischemic complications were the most common with $1.5 \%$ respectively. On the other hand, more than half (57\%) of the patients 
with non thrombolysed acute myocardial infarction presented complications: left ventricular dysfunction (30.6\%), ischemic complications (11.1\%), electrical complications $(7 \%)$ with a mortality of $5.6 \%$. Studies of mortality worldwide have shown that the mortality rate in patients with thrombolysis for acute myocardial infarction ranges from $7 \%$ to $14 \%$, while among non thrombolysed patients the mortality rate exceeds $20 \%$ [24]. Since our hospital does not have a catheterization room, the use of fibrinolytic agents is essential to obtain a reduction in the mortality rate and to improve the prognosis of patients with acute myocardial infarction, especially by applying thrombolytic treatment in the 3 early hours of the onset of precordial pain as has been proven by many studies [24] [27]. Conditions have been set up for carrying out thrombolysis at the level of community reference health centers, but the number of thrombolysed patients remains low. Albis and Guerrero found in a study from Columbia that $60 \%$ of patients with non thrombolysed myocardial infarction had complications [27] [28]. These results show us the importance of the administration of fibrinolytic treatment. An increase in the number of thrombolysed patients could reduce complications of acute myocardial infarction, thus reducing mortality.

\section{Limits}

The main limitation of this study was that streptokinase was the only fibrinolytic product (non selective fibrin) used, because it is the cheapest, while there are other fibrinolytic products (selective fibrin) which have less side effects and complications, but more expensive than streptokinase. Fibrinolytics fibrin selective was not available due to high costs.

\section{Conclusion}

The male and elderly were the most affected in our environment, thrombolysis was performed in more than half of the cases in the study. The efficacy criteria for fibrinolysis were observed in the majority of patients. The rate of major complication (bleeding) post thrombolysis was low. More than half of the cases of acute coronary syndrome with over-shift of non thrombolysed ST presented complications. An improvement in the level of education of the population and of health personnel on acute coronary syndrome with ST shift can increase the number of patients to be thrombolysed and consequently a reduction in mortality.

\section{Acknowledgements}

Thanks to the University Hospital of Las Tunas.

\section{Conflicts of Interest}

The authors declare no conflicts of interest for the publication.

\section{References}

[1] Sans, G.A. (2000) Ischemic Heart Disease. Farrera, 3, 533-552. 
[2] Braunwald, E., Zipes, D., Libby, P. and Massachussetts, W.B. (2007) Braunwald's Cardiologie. The Book of Cardiovascular Medicine. 7th Edition, W. B. Saunders Company, Philadelphia, 1266-1352.

[3] Roca, G.R. (2002) Internal Medicine Theme. 4th Edition, Medical Sciences Editorial, Havana, 392-418.

[4] McPherson, J.R. (2001) Reperfusion Therapy for Acute Myocardial Infarction. Emergency Medicine Clinics of North America, 19, 433-449. https://doi.org/10.1016/S0733-8627(05)70193-0

[5] Mele, E. (2010) Progress in Reperfusion after Acute Myocardial Infarction. The Situation in Latin America. Revista Española de Cardiología, 63, 12-19. https://doi.org/10.1016/S0300-8932(10)70149-4

[6] TIMI Study Group (1985) The Thrombolysis in Myocardial Infarction (TIMI) Trial-Phase I Findings. The New England Journal of Medicine, 312, 932-936. https://doi.org/10.1056/NEJM198504043121437

[7] Gruppo Italiano Per Lo Studio Della Strectochinasi Nell' Infarto Miocardico (GISSI) (1986) Effectiveness of Intravenous Thrombolytic Treatment in Acute Myocardial Infarction. Lancet, 1, 396-401.

[8] The GUSTO Investigators (1993) An International Randomized Trial Comparing Four Thrombolytic Strategies for Acute Myocardial Infarction. The New England Journal of Medicine, 329, 673-682. https://doi.org/10.1056/NEJM199309023291001

[9] Garcia, C., Sanz, G., Valle, V., Molina, L., Sala. J., Subirana, I., et al. (2010) Trends in In-Hospital Mortality and Six-Month Outcomes in Patients with a First Acute Myocardial Infarction. Change Over the Last Decade. Revista Española de Cardiología, 63, 1136-1144. https://doi.org/10.1016/S1885-5857(10)70227-9

[10] Martinez, P.F. (2011) Acute Myocardial Infarction Reperfusion Therapy Behavior in the Emergency Department. These for the Title of First Degree Specialist in Cardiology, Institute of Cardiology and Cardiovascular Surgery, Habana.

[11] Izaguirre, E. (1994) Thrombolytic Treatment of Acute Myocardial at the Institute of Cardiology and Cardiovascular Surgery in Havana. Thesis to Opt for the Rank of Specialist in Cardiology, Institute of Cardiology and Cardiovascular Surgery.

[12] De La Torre, L.C. and De Jesus, R.J. (2007) Causes of Non Thrombolysis during Acute Myocardial Infarction. Revista Cubana de Farmacia, 41, 42-47.

[13] Provincial Registry for Ischemic Heart Disease, Provincial Hospital Cardiology Department (2007) CQD Dr Ernesto Guevara Las Tunas.

[14] Health Analysis and Trend Unit (2011) Health Framework of Las Tunas Province, 2010-2011-2012. Provincial Center for Hygiene and Epidemiology, Las Tunas.

[15] Pupo Ceregido, A.E. (2009) Mortality from Acute Myocardial Infarction in the Intensive Care Unit. Las Tunas 2007-2009. Thesis for the Title of First Degree Specialist in Cardiology, Las Tunas.

[16] Alvarez, S. (2008) Theme of Integral General Medicine. Medical Sciences Editorial, 2, 536-556.

[17] Madan, Y. (2010) Association of Arteriogenic Risk Factors in Young People with Acute Myocardial Infarction. Revista Cubana de Cardiología y Cirugía Cardiovascular, 1, 326-394.

[18] National Directorate of Medical Registers and Health Statistics (2009) Health Statistics Yearbook. MINSAP, City of Havana, 35-41.

[19] Kannel, W.B. (2002) The Framingham Study, Historical Insight on the Impact of 
Cardiovascular Risk Factors Men versus Women. The Journal of Gender-Specific Medicine, 5, 27-37.

[20] Lopez, M., Jésus, A. and Lopez, D. (2009) Characterization of Acute Myocardial Infarction in the Simon Bolivar People's Clinic. Revista Cubana de Medicina General Integral, 25, 151-159.

[21] Danchin, N., Coste, P., Ferrières, J., Steg, P.-G., Cottin, Y., Blanchard, D., et al. (2008) Comparison of Thrombolysis Followed by Broad Use of Percutaneous Coronary Intervention with Primary Percutaneous Coronary Intervention for ST-Segment Elevation Acute Myocardial Infarction (FAST-MI). Circulation, 118, 268-276. https://doi.org/10.1161/CIRCULATIONAHA.107.762765

[22] Garcia, E. (2005) Interventionism in the Context of Acute Myocardial Infarction, Current Concepts, 58, 333-337.

[23] Sezer, M., Cimen, A., Aslanger, E., Elitok, A., Umman, B., Bugra, Z., et al. (2009) Effect of Intracoronary Streptokinase Administered Immediately after Primary Percutaneous Coronary Intervention on Long-Term Left Ventricular Infarct Size, Volumes, and Function. Journal of the American College of Cardiology, 54, 1065-1071. https://doi.org/10.1016/j.jacc.2009.04.083

[24] Antman, E.M., Hand, M., Armstrong, P.W,, Bates, E.R., Green, L.A., Halasyamani, L.K., et al. (2008) 2007 Focused Update of the ACC/AHA 2004 Guidelines for the Management of Patients with ST-Elevation Myocardial Infarction. A Report of the American College of Cardiology/American Heart Association Task Force on Practice Guidelines: Developed in Collaboration with the Canadian Cardiovascular Society Endorsed by the American Academy of Family Physicians: 2007 Writing Group to Review New Evidence and Update the ACC/AHA 2004 Guidelines for the Management of Patients with ST-Elevation Myocardial Infarction, Writing on Behalf of the 2004 Writing Committee. Circulation, 117, 296-329. https://doi.org/10.1161/CIRCULATIONAHA.107.188209

[25] Guèdes, R., Sanchez, F., Cabezas, I.E., Testar, J., Arocha, Y., et al. (2009) Lethality of Acute Myocardial Infarction. Mario Mugnos Military University Hospital Center. Matanzas. 2005-2007. Electronic Medical Journal, 31, 5.

http://www.revmatanzas.sld.cu/revista\%20medica/ano\%202009/vol5\%202009/tema $\underline{06 . \mathrm{htm}}$

[26] Ohman, E.M., et al. (2001) Intravenous Thrombolysis in Acute Myocardial Infarction. Chest, 119, 253S-277S. https://doi.org/10.1378/chest.119.1 suppl.253S

[27] FÉLix, J., Héctor, M., Guèdes, R., Gomez, R. and Guerra, H. (2009) Complications during the Early Course of Acute Myocardial Infarction in the Intensive Care Unit. Electronic Medical Journal, 31, 5.

http://www.revmatanzas.sld.cu/revista\%20medica/ano\%202009/vol5\%202009/tema $\underline{06 . \mathrm{htm}}$

[28] Albis, E., Guerrero, J. and Rojas, R. (2004). Intra-Hospital Prognosis of the Patient with Acute Coronary Syndrome according to the Age of Presentation. Colombian. Journal of Medicine, 9, 54-62. 